\title{
Carteira de Trabalho, artigo de luxo. O perfil psicossocial de trabalhadores informais em Salvador, Bahia.
}

\author{
Sônia Maria Guedes Gondim \\ Girleide Novaes Feitosa \\ Ivna Christine de Novaes Santos \\ Márcio de Oliveira Sá \\ Mirele Cardoso do Bonfim \\ Universidade Federal da Bahia
}

\begin{abstract}
Resumo
A pesquisa investigou o perfil psicossocial de trabalhadores informais que divulgavam seus serviços em anúncios de rádio e jornal na cidade do Salvador. Durante cinco meses foram registrados 638 anúncios distribuídos por 19 áreas ocupacionais. O objetivo da pesquisa era obter informações, como: motivos de ingresso na atividade informal, tempo de atuação, etc. Foram realizadas entrevistas por telefone com 73 anunciantes. Os entrevistados possuíam idade entre 30 e 39 anos, ensino médio, remuneração mensal entre 240 e 479 reais, e atuavam no setor informal há menos de 3 anos. Utilizou-se análise de conteúdo temática e análises quantitativas (qui-quadrado e Homals). O primeiro resultado foi que as principais áreas de atuação dos trabalhadores informais são: alimentação, multifuncionalidade e informática. Outro resultado foi que o cruzamento (qui-quadrado) entre os motivos de satisfação, insatisfação e barreiras, de um lado, e idade, escolaridade e tempo de atuação no mercado informal, de outro, revelou significância estatística nos casos: (1) insatisfação e faixa etária, (2) motivos de satisfação e escolaridade, e (3) motivos de satisfação e tempo de trabalho no mercado informal.
\end{abstract}

Palavras-chave: trabalho informal; perfil psicossocial do trabalhador

\begin{abstract}
Working card, a luxury item. The psycho-social profile of informal workers in Salvador, Bahia. The study investigated the psycho-social profile of informal workers that advertised their services through radio and newspaper announcements in the city of Salvador, Bahia. There were 638 ads registered during the 5 months of data collection, distributed in 19 areas of activity. The objective of the study was obtaining information about their reasons to get into the informal activity, time in operation, etc. Telephone interviews with 73 of the advertisers were conducted. The age of the interviewees was between 30 and 39 years, they had completed high school, and had a monthly remuneration between 240 and 479 reais (approximately US \$85-170 at the time of this writing), and worked in the informal sector for less than 3 years. Thematic content analysis and quantitative procedures, such as chi-square and Homals, were the procedures of analysis employed. The first result was that the main work areas of the informal workers were: food services, multi-functionality and information technology. Another important result was the interaction (chi-squared) between the motives of satisfaction, dissatisfaction and barriers, on the one hand, and age, level of education and time operating in the informal market, on the other, revealed statistical significance in three cases: (1) dissatisfaction and age group, (2) satisfaction motives and level of education, and (3) satisfaction motives and time of work in the informal market.
\end{abstract}

Keywords: informal work; psycho-social profile of the worker; informal market

A ssiste-se nos últimos anos ao crescimento expressivo de trabalhadores que se encontram exercendo atividades caracterizadas como informais (O trabalho informal, s.d.; Central Única dos Trabalhadores/CUT, s.d.). Acredita-se que isso esteja ocorrendo em virtude da tendên- cia mundial de eliminação de postos de trabalho (Oliveira, 2004), em especial pela adoção de novas tecnologias e estilos de gestão (Borges \& Yamamoto, 2004), o que contribui para o aumento do número de trabalhadores que migram do setor formal para o informal. Em sintonia com esta linha de raciocí- 
nio, Nunes (2002) argumenta que o crescimento regular da informalidade no Brasil (58\% da população economicamente ativa - PEA) é devido, em grande parte, às hodiernas transformações do mundo do trabalho - terceirização, aumento do desemprego e diminuição do emprego na indústria.

Pastore, em entrevista ao Estado de São Paulo, em junho de 2003, previu com base no PNAD (Pesquisa Nacional de Amostra Domiciliar) de 2001 do IBGE (Instituto Brasileiro de Geografia e Estatística), que teríamos naquele mesmo ano em torno de 45 milhões de pessoas no setor informal distribuídas em cinco categorias: (1) empregados de empresas (42,3\%), (2) trabalhadores por conta própria (33,3\%), (3) trabalhadores sem remuneração (13,3\%), (4) trabalhadores domésticos (8,4\%) e (5) empregadores (2,7\%).

Além da concordância da maioria dos autores que discorrem sobre o assunto, em afirmar que o trabalho informal cresceu expressivamente nos últimos anos e que inclui uma diversidade de segmentos da população economicamente ativa (Mafra, Tavares, Eiras, \& Mangini, 2002), tampouco parece haver controvérsia de que a expansão do trabalho informal esteja localizada no segmento das micro e pequenas empresas. No final da década de 1990, a estimativa era de que $55 \%$ dos novos postos de trabalho surgiram em micro e pequenas empresas (SEBRAE, s.d.).

Apesar de o termo informal ter um significado relativamente simples e, a princípio, sugerir que seja tudo aquilo que não é formal, sua aplicação irrestrita no contexto abrangente do mundo do trabalho reveste-se de complexidade, visto o conjunto de atividades e dimensões bastante diversificadas que o rótulo pretende contemplar (Spínola, 2000). Há autores, como Noronha (2003), que acreditam ser necessário substituir o termo informal, porque as atividades econômicas exigem sempre algum nível de institucionalização ou formalização, quer seja por lei, quer por acordos coletivos ou práticas sociais, tornando sem sentido falar de informalidade. Então, não é difícil concluir que, ao se tentar investigar o tema, uma das primeiras barreiras a enfrentar é a sua conceituação.

Existem inúmeras definições para a expressão mercado informal, o que torna seu significado bastante amplo e impreciso. Fagundes (1992) corrobora essa afirmação, e acredita ainda que definições que incluam aspectos como renda e tamanho da empresa só aumentam a confusão conceitual já existente. Outros autores, entre eles Dalbosco (1999), também acreditam que a diversidade constitutiva presente no mercado informal obstaculiza a criação de uma única definição, dificuldade essa não apenas acadêmica, mas também da parte do governo, o que segundo Noronha (2003) tem limitado o avanço da discussão sobre o tema. No texto da CUT já mencionado (consultado em 20 de agosto de 2004), há duas formas básicas de definir trabalho informal: (1) aquele cujas atividades produtivas são realizadas à margem da legislação trabalhista em vigor no país; e (2) aquele vinculado a trabalhadores por conta própria e também a empregadores e empregados de pequenas empresas com baixos níveis de produtividade.
A expressão setor informal surge pela primeira vez em 1972, no Quênia, África, no Relatório sobre emprego e renda, da Organização Internacional do Trabalho (OIT), ocasião em que foram propostas as denominações setor formal e informal, em substituição a setor moderno (tecnologia avançada), setor tradicional (tecnologia atrasada) e subemprego. No texto da OIT, o setor informal é visualizado como uma nova estratégia de desenvolvimento e é definido como sendo composto por empresas de pequeno porte, mercados simples, competitivos e não-regulados, que empregam recursos locais, tecnologia adaptada e uso intenso de mão-de-obra (Fagundes, 1992; Morrone \& Mendes, 2003). Atualmente a própria OIT adota uma nova conceituação para o setor informal, que passa a ser definido como um agrupamento de atividades de baixa produtividade, com trabalhadores independentes e empresas muito pequenas ou não-organizadas.

Ao dar seguimento à discussão sobre a conceituação de setor informal, Spínola (2000) afirma que é comum distinguir os setores formal e informal por critérios, tais como, nível tecnológico, porte da empresa e existência de registro legal da empresa e dos trabalhadores. Esta prática, entretanto, possui limitações, uma vez que o porte de uma empresa não informa se ela possui ou não trabalhadores com registro legal. $\mathrm{Na}$ informalidade estão aquelas atividades que fogem às regras jurídicas institucionais ou que são alternativas ao desemprego, estando nela incluídos tanto subempregados quanto profissionais liberais.

De acordo com Fagundes (1992), há duas definições para trabalho informal: não assalariado (em contraposição ao trabalho formal assalariado) e ocupações expostas ou não à legislação trabalhista (trabalhadores autônomos). Para Dalbosco (1999), o setor formal é constituído por postos ocupacionais disponíveis nas organizações formais e de serviços, que são requeridos pelos grupos de maior renda; ao passo que o setor informal é o resultado do excedente da força de trabalho não incorporado ao setor formal, incluindo a maior parte dos trabalhadores por conta própria, os serviços domésticos, e os ocupados (patrões e empregados) em pequenas empresas não constituídas formalmente. Dalbosco assevera que não se trata de uma concepção dualista e de exclusão, pois os dois setores estabelecem entre si relações de competição e de complementaridade no mercado. Para a Secretaria de Indústria e Comércio do Estado da Bahia (1983), o trabalho informal é integrado por todas as pessoas que desenvolvem atividades sem carteira assinada e trabalham por conta própria, isoladamente, ou com auxílio de membros da família, quer seja sob a forma de trabalho autônomo, quer seja organizada em micro-empresa.

As informações que esquadrinhamos até o momento permitem afirmar que a informalidade possui pelo menos três dimensões: (1) a informalidade em relação às instâncias reguladoras municipais, estaduais e federais, com repercussões nos registros, pagamento de impostos e cumprimento de legislação trabalhista; (2) a informalidade em relação ao contrato com clientes para os quais se presta serviços, com impactos na ausência de emissão de notas e sistemas for- 
mais de cobrança que regulem a relação cliente-consumidor, o que ocorre, por exemplo, não só com o trabalhador autônomo (um ambulante), como também em algumas modalidades de terceirização (trabalhadores temporários e cooperativas de prestação de serviços); e (3) a informalidade em relação à instância empregadora, em que fica evidente a precariedade nas relações de trabalho, pois o trabalhador, embora mantenha uma relação com o empregador, não possui carteira assinada, o que gera impacto imediato nos seus direitos trabalhistas.

É preciso ter em mente, entretanto, que o trabalho informal não é apenas uma atividade econômica não legalizada, mas uma prática de sobrevivência instituída, em grande parte decorrente de condições sociais precárias, e que vem crescendo no contexto da reestruturação produtiva. Com efeito, o setor informal está deixando de ser percebido apenas como um setor marginal, para ser visualizado como uma possibilidade de inclusão em um provável processo de formalização (Dalbosco, 1999; Nunes, 2002). Outro autor que se aproxima deste ponto de vista é Fagundes (1992), que afirma que o setor informal não é apenas uma alternativa àqueles que não tiveram outras oportunidades no mercado formal, porque há também no setor informal trabalhadores qualificados, com ganhos relativamente elevados. Um exemplo é o de algumas baianas de acarajé da cidade de Salvador, cuja renda mensal está bem acima dos 20 salários mínimos.

Dalbosco (1999) traz ainda uma outra contribuição ao debate, ao alertar para o fato de que o crescimento do setor informal depende da estrutura do mercado, visto que em cenários de concorrência perfeita (entre iguais), ele reúne mais chances de sustentação e crescimento do que em cenários de oligopólios (concorrência entre desiguais). Dito de outro modo, é relativamente fácil inserir-se precariamente no mercado informal, mas torna-se difícil o trabalhador nele permanecer na mesma atividade, como em casos cujos investimentos em equipamentos e ferramentas de trabalho são necessários para a manutenção e expansão do negócio.

Apesar de encontrarmos na literatura uma diversidade de definições e uma complexidade em se caracterizar o setor informal, não se encontra disponível em profusão uma discussão mais aprofundada sobre o perfil psicossocial dos trabalhadores informais. Com efeito, temos acesso a dados demográficos gerais, sobre sexo, idade, rendimento mensal, escolaridade, etc., mas compreendemos muito pouco como o trabalhador informal percebe e avalia a sua realidade sócioocupacional. Uma das exceções de que temos conhecimento é a pesquisa realizada com trabalhadores das feiras de artesanato e de ambulantes realizadas no sul do Estado de Minas Gerais (Mafra et al., 2002), embora sua ênfase tenha recaído na responsabilidade do poder público local em oferecer suporte para as atividades informais, deixando de abordar o perfil desse trabalhador.

O principal objetivo da pesquisa aqui relatada foi o de traçar um perfil de um dos segmentos de trabalhadores informais, o daqueles que divulgam seus serviços ou produtos em anúncios de jornais ou anúncios gratuitos de uma rádio local.
Além de identificar dados demográficos, procurou-se compreender os motivos de ingresso no mercado informal, o tempo de atividade informal, os fatores de satisfação e de insatisfação, bem como as barreiras e dificuldades encontradas para sua permanência e sobrevivência no mercado. Embora se admita que os dados e conclusões desta pesquisa tenham restrito poder de generalização, visto que se trata de um estudo descritivo que mapeou apenas um segmento de trabalhadores informais, eles oferecem uma perspectiva de análise complementar a um tema abrangente e diversificado que contempla inúmeras idiossincrasias, qual seja o do setor e mercado informal.

\section{Método}

O desenvolvimento da pesquisa incluiu duas etapas. A primeira foi a de identificar, classificar e contar os tipos de anúncios veiculados, quer em jornal, quer transmitidos gratuitamente por uma rádio local, via programa especialmente criado para este fim. Depois deste mapeamento, foi feita uma categorização temática (Bardin, 1970; Bauer, 2000), baseando-se no conteúdo desses anúncios, tendo sido compostas 19 categorias. Após esta categorização, os dados foram lançados no programa SPSS (Statistical Package for Social Science) com o objetivo de obter informações sobre distribuição de freqüência por categoria, de modo que fossem selecionados os entrevistados, respeitando a representatividade dessas categorias.

O objetivo da segunda etapa, por sua vez, foi o de obter um contato mais direto com o trabalhador informal, visto que os anúncios tanto de rádio quanto de jornais forneciam escassas informações sobre a pessoa que oferecia os seus serviços. O propósito inicial era o de realizar entrevistas em profundidade, permitindo uma análise mais qualitativa deste trabalhador. Porém, diante das dificuldades encontradas, especificadas na próxima seção, optou-se por realizar entrevistas telefônicas. E embora tais entrevistas tenham contemplado tanto questões abertas quanto fechadas, viabilizando, no primeiro caso, o procedimento de análise categórica temática, o pequeno volume de informações colocou obstáculos a uma análise qualitativa mais aprofundada. Isto porque entrevistas telefônicas não constituem uma via pela qual as pessoas falam de modo mais detalhado sobre suas experiências pessoais, o que compele o pesquisador a limitar o roteiro de entrevista, quer em número de tópicos, quer no tempo dedicado a cada tópico. Isto fez com que houvesse uma reorientação dos procedimentos de análise e, ao invés de realizar apenas uma análise qualitativa, utilizou-se o programa SPSS para executar alguns cruzamentos, visto que foi possível entrevistar 73 pessoas, quantidade que justificava análises quantitativas.

As respostas dos entrevistados às questões abertas viabilizaram a análise categorial temática e seu tratamento como variável nominal, o que repercutiu na escolha dos tipos de análises estatísticas. A análise cruzada de freqüências por meio do qui-quadrado $\left(\chi^{2}\right)$ é um procedimento indicado para 
esses casos, e foi justamente por isso que foi privilegiado (ver Morgan \& Griego, 1998; Pestana \& Gageiro, 1998).

A análise fatorial de correspondência Homals também é um procedimento de análise passível de ser usado quando as variáveis da pesquisa são nominais. Trata-se de uma técnica de redução e agrupamento de dados, que permite representar três ou mais variáveis nominais em poucas dimensões, geralmente duas. Seu produto é um gráfico de quantificação do número de casos distribuídos em duas (ou mais) dimensões de análise. Cada dimensão possui um valor próprio que mede a informação dada. Quanto mais próximo de 1, mais poder de análise a dimensão possui: dimensão 1 , corte vertical de análise, dimensão 2, corte horizontal de análise (Pestana \& Gageiro, 1998). Em sendo assim, a análise que está sendo aqui relatada foi tanto um produto quanto um insumo na sustentação de tratamento estatístico. Os fragmentos de falas mencionados na seção de apresentação dos resultados foram escolhidos na medida em que serviam para justificar, ilustrar e argumentar a predominância de categorias que revelou significância estatística nos cruzamentos decorrentes do quiquadrado, e nos agrupamentos feitos pelo procedimento Homals. É com base neste entendimento que se afirma que a pesquisa usou de modo complementar a abordagem qualitativa e quantitativa.

\section{Procedimentos}

Durante 5 meses (setembro de 2003 a janeiro de 2004) foram registrados os anúncios de oferta de serviços em uma rádio e em um jornal locais, totalizando 638 anúncios. No caso da rádio, os anúncios eram lidos por uma repórter e por serem muito resumidos, ao incluírem apenas o primeiro nome da pessoa, o serviço ou produto oferecido e o telefone de contato, houve necessidade de complementação das informações por meio de entrevistas por telefone realizadas, posteriormente, com 73 dos anunciantes. A seguir serão detalhadas informações a respeito dos procedimentos utilizados durante a coleta dos anúncios de oferta de serviços, explicitados os temas abordados por meio das entrevistas feitas com os anunciantes e, por último, descrita a forma de análise de dados.

Os anúncios gratuitos de rádio eram veiculados em duas edições diárias de 5 a 10 minutos, e cada membro da equipe de pesquisa ficou responsável por ouvi-los e anotar os dados em dias específicos da semana. Os anúncios coletados em jornal foram acompanhados semanalmente, nas edições de domingo. A equipe reuniu essas informações, levando em conta a fonte da qual o anúncio foi extraído, o telefone do anunciante e a freqüência do anúncio por área de abrangência. Por meio da análise categorial temática a posteriori foram identificadas 19 áreas de abrangência desses serviços: alimentos, construção civil, informática, vestuário, educação, artes, serviços domésticos, vídeo e fotografia, vigilância e segurança, condutores e motoristas, atendimento, organização de eventos, estética corporal, cuidadores, serviços de mensagem, eletroeletrônicos, contabilidade, multifuncional e, por último, diversos. É importante destacar que na categoria chamada de multifuncional foram incluídos aqueles anúncios que abrangiam mais de uma área de atuação, ou seja, ofertas de serviços em duas ou mais das áreas identificadas. Na categoria de diversos foram alocados os anúncios episódicos e inusitados, que não se enquadravam em nenhuma das outras categorias, como um trabalhador que oferecia seus serviços para se vestir de Papai Noel na época do Natal e um consultor de loteria, que ajudava as pessoas a aumentarem a sua probabilidade de acertar nos jogos de azar.

Além disso, em alguns casos tornou-se necessário criar subcategorias para a área de abrangência, como na área de alimentos, na qual foi necessário dividir entre aqueles que produzem alimentos, os que os comercializam, os que ministram cursos e os que na verdade não oferecem serviços na área, mas estão à procura de emprego e aproveitam a oportunidade do anúncio gratuito para divulgar a sua disponibilidade.

\section{Instrumentos}

Como mencionado anteriormente, os anúncios de jornal e da rádio forneciam apenas informações sobre a atividade exercida pelo trabalhador e seu telefone para contato. Ao concluir que esses dados eram insuficientes para identificação do perfil psicossocial dos trabalhadores do mercado informal, fez-se necessário realizar entrevistas com os anunciantes. Para isso, foram reunidos os números de telefone fornecidos, levando em conta a diversidade das 19 áreas mapeadas, e feita entrevista inicial para saber do interesse em participar da pesquisa. Como citado anteriormente, o propósito inicial era o de fazer as entrevistas face a face, gravandoas para posterior transcrição e análise qualitativa. Porém, a partir dos primeiros contatos telefônicos, constatou-se que haveria dificuldade em agendar as entrevistas, pois as pessoas que anunciavam seus serviços residiam em bairros distantes, e teriam de se deslocar para o local no dia e hora marcados. Por isso, optou-se por realizar breves entrevistas telefônicas (que duraram cerca de 5 a 10 minutos). Os dados coletados nas entrevistas foram anotados em uma folha de papel com as perguntas a serem feitas, sobre os seguintes temas: (1) motivo de inserção do profissional no mercado informal (questão aberta); (2) tempo de atuação desse profissional no mercado informal (questão fechada); (3) fatores de satisfação e insatisfação (questão aberta); (d) dificuldades e barreiras encontradas para sobreviver nesse mercado (questão aberta); (4) remuneração mensal (questão fechada na qual foram lidas faixas de valores) e (5) idade e escolaridade (questão fechada).

\section{Análise dos dados}

Para a análise das questões abertas foram criadas unidades temáticas (Bardin, 1970; Bauer, 2002), conforme apresentado na Tabela 1. As categorias por tema foram lançadas no SPSS, para análises de distribuição de freqüência e de quiquadrado, visando a avaliar se havia diferenças significativas do ponto de vista estatístico no cruzamento, de um lado, das variáveis idade, remuneração, tempo de trabalho e escolaridade, e, de outro, das variáveis motivos de ingresso, fatores de satisfação, fatores de insatisfação e barreiras ou dificuldades de sustentação do negócio. 
Tabela 1

Categorização das respostas dadas pelos participantes

\begin{tabular}{|c|c|c|}
\hline Questões & Categorias & Respostas \\
\hline 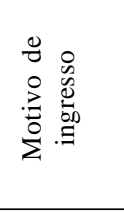 & $\begin{array}{l}\text { 1. Experiência anterior } \\
\text { 2. Desemprego } \\
\text { 3. Complementação } \\
\text { 4. Aplicação de curso } \\
\text { 5. Escolha pessoal } \\
\text { 6. Melhor renda }\end{array}$ & $\begin{array}{l}\text { Família, aprendeu com o pai, amigos e história pessoal } \\
\text { Perdeu emprego e não consegue outro por conta da idade, falta de oportunidades, falta de qualificação } \\
\text { Atividade paralela ao trabalho formal, complementação de aposentadoria, ajudar a família } \\
\text { Aplicação prática de curso feito anteriormente } \\
\text { Escolha e necessidade de ocupar o tempo } \\
\text { Melhorar a remuneração }\end{array}$ \\
\hline 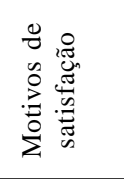 & $\begin{array}{l}\text { 1. Investimento pessoal } \\
\text { 2. Clientela } \\
\text { 3. Sustentação } \\
\text { 4. Retorno }\end{array}$ & $\begin{array}{l}\text { Gosta do que faz, esforço, luta e dedicação } \\
\text { Clientela fiel, tem paciência com os clientes, presta bons serviços } \\
\text { Não tem patrão, flexibilidade de horário, despesas pequenas para manutenção e experiência. } \\
\text { Independência financeira, realização profissional, ter uma ocupação, estar adaptado, conseguiu criar a } \\
\text { família }\end{array}$ \\
\hline 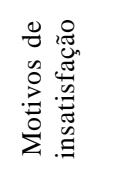 & $\begin{array}{l}\text { 1. Retorno } \\
\text { 2. Clientela } \\
\text { 3. Sustentação } \\
\text { 4. Investimento / capital }\end{array}$ & $\begin{array}{l}\text { Rendimento insuficiente, falta de sorte, aquém das expectativas, rendimento incerto, sem direitos } \\
\text { Calote e dificuldade de cobrança, exploração, clientela sem dinheiro, sazonalidade de demanda, falta de } \\
\text { reconhecimento } \\
\text { Custo de manutenção e infra-estrutura, falta de habilidade e qualificação, concorrência } \\
\text { Investimento arriscado, falta de capital }\end{array}$ \\
\hline 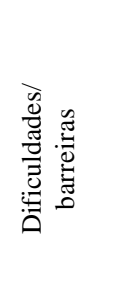 & $\begin{array}{l}\text { 2. Concorrência } \\
\text { 3. Apoio do governo } \\
\text { 4. Cliente } \\
\text { 5. Retorno }\end{array}$ & $\begin{array}{l}\text { Divulgação, falta de instrução e qualificação, necessidade de se manter atualizado, baixa capacidade de } \\
\text { negociação, custo de manutenção e matéria-prima, dificuldade de montar equipe de trabalho nos } \\
\text { momentos em que há maior demanda } \\
\text { Competitividade e concorrência, pressão para legalização (senão não consegue competir), concorrên- } \\
\text { cia desleal (rebaixamento de preços pelo concorrente pessoa física) } \\
\text { Falta de apoio do governo, burocracia, impostos, investimento de risco, falta de crédito } \\
\text { Rede de relacionamentos - desconfiança do cliente, falta de recursos do cliente, dificuldade de cobrar } \\
\text { do cliente, desvalorização do cliente } \\
\text { Rendimento incerto, insegurança de rendimento }\end{array}$ \\
\hline
\end{tabular}

Como citado no início desta seção de método, os dados também foram submetidos à análise fatorial por correspondência (Homals), com o intuito de investigar de que modo as respostas dos participantes se distribuíam em grupos homogêneos.

\section{Resultados e discussão}

Esta seção apresenta e discute conjuntamente os 638 anúncios registrados em cinco meses de publicação no “Caderno de Empregos” do jornal dominical e na rádio, assim como os resultados das entrevistas por telefone com 73 trabalhadores informais.

\section{Área de atuação dos trabalhadores informais}

No que diz respeito aos anúncios de rádio e de jornal coletados, as áreas em que mais apareceram anúncios foram de alimentação, multifuncional e informática. A Tabela 2 indica, para cada categoria de atividade, a freqüência com que os anúncios apareceram, assim como a correspondente porcentagem.

Algumas áreas de abrangência se destacaram em relação às demais pela presença de subcategorias e serão feitos alguns comentários sobre elas. Nas áreas alimentação, eletroeletrônicos e construção civil, as ofertas de serviços se concentraram, em sua maior parte, na produção, instalação ou manutenção de materiais. Vale ressaltar que no setor de alimentos encontramos uma especificidade, visto que alguns trabalhadores, ao mesmo tempo em que produziam, também se encarregavam da venda de seus produtos.

Tabela 2

Freqüência (absoluta e percentual) dos anúncios pelas categorias encontradas

\begin{tabular}{lrr}
\hline \multicolumn{1}{c}{ Área de abrangência } & Freqüência & \multicolumn{1}{c}{$\%$} \\
\hline Alimentos & 112 & 17,6 \\
Multifuncional & 86 & 13,5 \\
Informática & 62 & 9,7 \\
Atendimento & 38 & 6,0 \\
Serviços de mensagem & 36 & 5,6 \\
Estética corporal & 35 & 5,5 \\
Diversos & 34 & 5,3 \\
Eletroeletrônicos & 33 & 5,2 \\
Construção civil & 32 & 5,0 \\
Vestuário, cama, mesa e banho & 32 & 5,0 \\
Condutores e motoristas & 31 & 4,9 \\
Cuidadores & 24 & 3,8 \\
Artes & 22 & 3,4 \\
Educação & 21 & 3,3 \\
Serviços domésticos & 21 & 3,3 \\
Contabilidade & 6 & 0,9 \\
Organização de eventos & 5 & 0,8 \\
Vídeo, fotografia e filmagem & 4 & 0,6 \\
Vigilância & 4 & 0,6 \\
\hline Total & 638 & 100 \\
\hline
\end{tabular}


No caso dos condutores e motoristas, a maior parte deles procurava emprego, o que sugere que os anúncios de rádio, por serem gratuitos, eram visualizados muito mais como uma via pela qual a pessoa divulgava sua condição de desocupado, do que oferecia seus serviços.

Quanto à área de informática havia anunciantes que ofereciam cursos $(n=8)$, que trabalhavam com manutenção $(n=5)$ e outros que procuravam emprego $(n=3)$. Na categoria dos cuidadores, a maior parte das pessoas (18 das 24 pessoas) anunciou seus serviços para cuidar de idosos e pessoas doentes, enquanto apenas duas delas eram babás.

Na área de estética corporal, 13 das 35 pessoas ofereciam serviços de massagem. Oito anunciantes ofereciam seus serviços para fazer depilação, e três se apresentavam como cabeleireiros. Os demais trabalhavam com atividade física, venda de cosméticos ou procuravam emprego.

No setor de atendimento, 19 pessoas faziam-no de modo direto, ou seja, ofereciam seus serviços para trabalhar como garçons, atendentes ou recepcionistas; 13 procuravam emprego no mercado formal e as pessoas restantes anunciaram serviços para fazer atendimento indireto, como o de telefonia.

Na área de artes, 10 das 22 pessoas que anunciaram seus serviços, trabalhavam com design e arte final, enquanto outras trabalhavam com música $(n=4)$ e artesanato $(n=4)$. Outros quatro anunciantes faziam atividades relacionadas a danças, pinturas e esculturas, o que incluía dar aulas de forró e vender obras de arte.

No setor de vestuário, cama mesa e banho, os anúncios se concentraram na parte de vestuário, sendo estes os responsáveis por 11 dentre os 32 veiculados. Essas pessoas ofereciam seus serviços especificamente para reformar e customizar roupas.

Para as demais oito áreas de abrangência não foi necessário criar subcategorias. Na área de serviços gerais, os anunciantes eram diaristas, e na área de vigilância e segurança, apresentavam-se como vigias. O mesmo aconteceu com as áreas de vídeo e fotografia, organização de eventos, serviços de mensagem e contabilidade.

\section{Conversando ao telefone com o trabalhador informal: em busca da identificação de um perfil.}

Das 73 pessoas entrevistadas, 36 eram homens e $37 \mathrm{mu}$ lheres. A maior parte delas se encontrava na faixa etária de 30 a 39 anos $(n=25)$, seguida da faixa de 40 a 49 anos $(n=18)$, de 19 a 29 anos $(n=13)$ e de 50 a 59 anos $(n=12)$. Cinco participantes restantes estavam na faixa de 60 a 69 anos.

Quanto à escolaridade dos entrevistados, a maior parte (43 pessoas, ou 58,9\%) tinha concluído o ensino médio. Oito pessoas haviam cursado apenas o ensino fundamental, número também encontrado entre os participantes com ensino superior incompleto. Cinco entrevistados tinham concluído o ensino fundamental, cinco não haviam concluído o ensino médio e quatro apresentavam ensino superior completo.
Outro dado também coletado pela entrevista foi o tempo de permanência desses profissionais na informalidade. Entre os 73 entrevistados, cinco se encontravam há menos de 1 ano no mercado informal, 16 estavam entre 1 e 3 anos, seguidos pelos 13 profissionais que nele permaneciam de 3 a 5 anos. Na seqüência, nove profissionais já atuavam na informalidade de 7 a 10 anos; oito, de 10 a 15 anos; sete, de 5 a 7 anos; cinco, de 15 a 20 anos; cinco, há mais de 30 anos; três, de 25 a 30 anos e apenas uma pessoa estava nesse mercado entre 20 e 25 anos. Em síntese, 29 dos 73 trabalhadores entrevistados atuavam no mercado informal no máximo há 5 anos.

No que diz respeito à área de atividade, houve maior concentração na categoria diversos $(\mathrm{n}=10)$ e na multifuncional $(\mathrm{n}=8)$. Deve-se levar em conta, não obstante, a grande variedade de atividades prestadas pelos inseridos nestas duas áreas, visto que diversos incluiu profissionais que ofereciam serviços inusitados (vestir-se de Papai Noel) e a área denominada multifuncional incluiu trabalhadores que ofereciam serviços em mais de uma área de atuação. Este cenário revela que uma parte expressiva dos profissionais do mercado informal necessita diversificar as atividades oferecidas, para ampliar suas oportunidades, contribuindo para que o setor venha a ser caracterizado muito mais como de atividades genéricas ("bicos”), do que de atividades especializadas.

As outras áreas que tiveram maior número de pessoas entrevistadas foram a de condutores e motoristas $(\mathrm{n}=7)$, vestuário $(\mathrm{n}=6)$ e alimentação $(\mathrm{n}=4)$. A área de informática, que apareceu em terceiro lugar na oferta de serviços anunciados, teve apenas dois entrevistados. Isto é explicado pelo fato de que ao fazer os contatos via telefone com as pessoas que anunciaram seus serviços no rádio e no jornal, a equipe de pesquisa enfrentou dificuldades, pois vários números de telefone não se encontravam mais ativos ou o anunciante havia encerrado suas atividades. Esses fatos podem ser indícios da fragilidade de alguns empreendimentos no mercado informal em se manterem atuantes, e acabou sendo decisivo na composição do grupo de entrevistados.

A entrevista também incluiu uma questão sobre a remuneração mensal. Vinte e um deles disseram ter renda entre 240 e 480 reais, e 18 disseram receber mais de 600 reais. Aqueles que recebiam menos de um salário somaram 17 pessoas, e oito disseram ter renda entre 480 a 599 reais. Nove participantes, no entanto, demonstraram dificuldade em especificar o valor que recebiam mensalmente, justificando que seus rendimentos não eram fixos, variando muito de um mês para outro.

Quanto à ocupação das pessoas entrevistadas, 55 (75,34\%) não exerciam outra atividade além da informal, e 18 eram aposentados ou tinham alguma outra atividade, tais como um trabalho formal, uma atividade informal a mais, ou ainda um curso universitário. 
Motivos de satisfação, insatisfação e barreiras: o que pensa o trabalhador informal?

Os resultados do cruzamento das variáveis motivos de satisfação, insatisfação e barreiras ou dificuldades, de um lado, e das variáveis idade, escolaridade e tempo de informalidade, de outro, obtiveram (no teste de qui-quadrado) resultados estatisticamente significantes em apenas dois casos.

A variável insatisfação apresentou rejeição da independência $\left(\chi^{2}=13,565 ; g l=6 ; p=0,035\right)$ em relação à categoria retorno do trabalho informal ao ser cruzada com a idade dos participantes e, mais especificamente, para os participantes de 30 a 49 anos (Tabela 3). Uma participante de 34 anos, que possui ensino médio completo e trabalha com vídeo, foto e filmagem, afirmou: "Estresse de você saber que hoje tem, mas amanhã não sabe se vai ter”, deixando transparecer que na informalidade o retorno financeiro é ainda mais incerto que no setor formal.

A variável motivos de satisfação teve independência rejeitada em relação aos participantes com escolaridade de ensino médio (nível estatisticamente significativo, $\operatorname{com} \chi^{2}=16,68 ; g l=6 ; p=0,011$ ). As distribuições de freqüências cruzadas dessas variáveis estão apresentadas na Tabela 4.
A maior parte dos motivos de satisfação entre as pessoas que possuem ensino médio se concentra na clientela e no tipo de retorno (Tabela 4). Uma participante de 24 anos, com ensino médio completo, há um ano e seis meses trabalhando no mercado informal em funções variadas, afirmou que é bem sucedida porque tem clientes fiéis até hoje, enquanto outra participante que também cursou o ensino médio, de 44 anos e atuando há 22 anos na área de estética no setor informal declarou que é bem sucedida porque tem a amizade e a confiança das clientes, freqüenta a casa delas e conversam muito. Em relação ao retorno pessoal, um participante que trabalha há seis anos informalmente como condutor, tendo 48 anos e ensino médio completo, declarou que se sentia valorizado na relação profissional, pois realizava o trabalho com perfeição, qualidade e tinha prazer com isso, acrescentando que sua remuneração era relativa, mas permitia manter seu padrão de vida.

Nos quatro gráficos produzidos pela análise fatorial de correspondência (Homals) a dimensão 1 foi a que apresentou maior poder de análise. Assim, as respostas encontradas constituem dois grupos homogêneos, um situado no lado esquerdo e outro no direito de cada gráfico. A Figura 1 apresenta resultados da correspondência entre motivos de ingresso e motivos de satisfação.

Tabela 3

Cruzamento de motivos de insatisfação e idade $(n=38)$

\begin{tabular}{lrcccr}
\hline \multirow{2}{*}{ Idade } & \multicolumn{5}{c}{ Motivos de insastifação } \\
\cline { 2 - 7 } & Retorno & Cliente & Sustentação & Investimento & Total \\
\hline 19 a 29 & 1 & 6 & - & 1 & 8 \\
30 a 49 & 12 & 3 & 5 & 4 & 24 \\
$50 \mathrm{ou}+$ & 1 & 2 & 2 & 1 & 6 \\
\hline Total & 14 & 11 & 7 & 6 & 38 \\
\hline
\end{tabular}

Nota: O valor total (38) equivale ao número de motivos de insatisfação mencionados pelos entrevistados, não mantendo uma correspondência direta com o número de entrevistados.

Tabela 4

Cruzamento de motivos de satisfação e escolaridade $(n=48)$

\begin{tabular}{lrcccr}
\hline \multirow{2}{*}{ Nivel de escolaridade } & \multicolumn{5}{c}{ Motivos de insastifação } \\
\cline { 2 - 6 } & Retorno & Cliente & Sustentação & Investimento & Total \\
\hline Ensino fundamental & 1 & 6 & - & 1 & 8 \\
Ensino médio & 12 & 3 & 5 & 4 & 24 \\
Ensino superior & 1 & 2 & 2 & 1 & 6 \\
Total & 14 & 11 & 7 & 6 & 38 \\
\hline
\end{tabular}

Nota: O valor total (48) equivale ao número de motivos de satisfação mencionados pelos entrevistados, não mantendo uma correspondência direta com o número de entrevistados. 


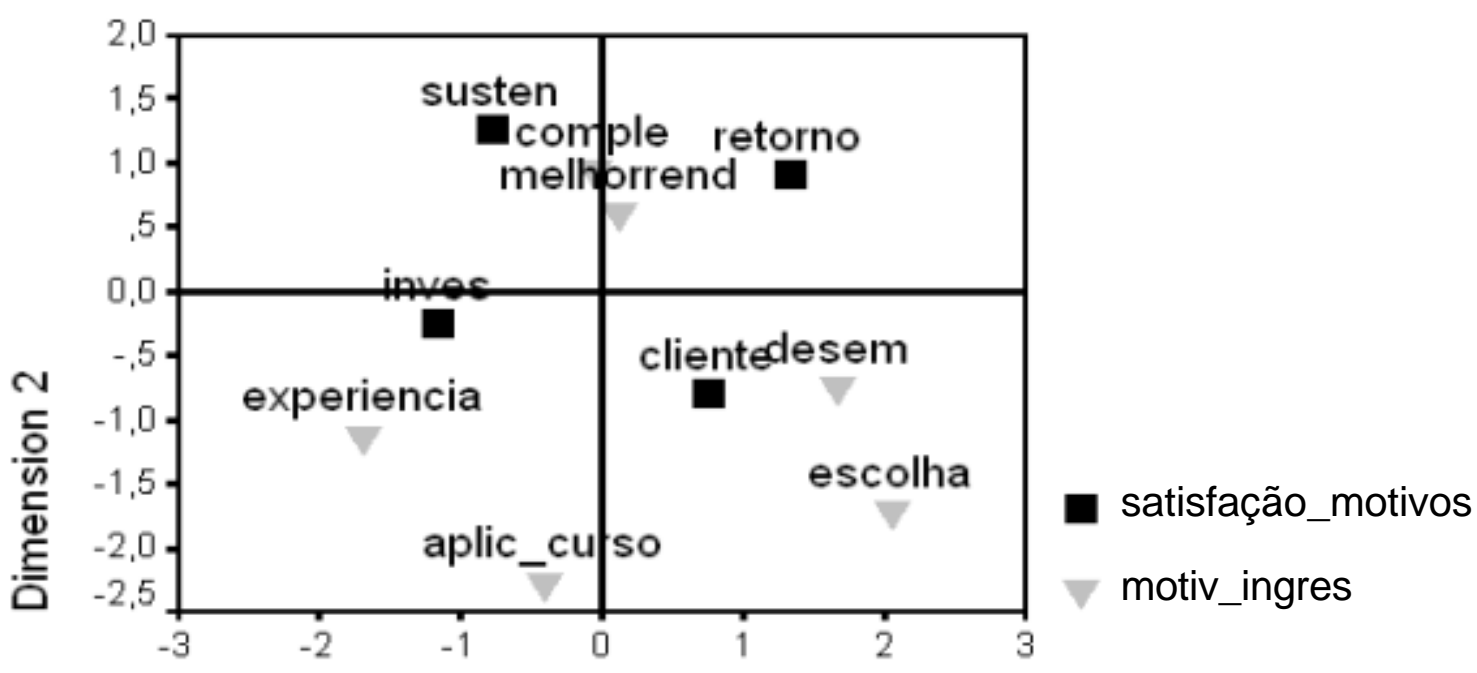

\section{Dimension 1}

Figura 1. Correspondência entre motivos de ingresso e motivos de satisfação (valor próprio - dimensão 1: 0,838; dimensão 2: 0,41).

O primeiro grupo de respostas, situado no lado esquerdo, reúne os motivos de ingresso na informalidade vinculados à experiência anterior, aplicação de curso e complementação, e os motivos de satisfação investimento pessoal e sustentação (flexibilidade de horário, ausência de patrão, experiência e despesas pequenas para a manutenção). Pode-se dizer que as pessoas que se inserem no setor informal para complementar sua renda, necessitam conciliar as duas atividades, sendo a flexibilidade de horário, nesse caso, uma das vantagens da informalidade, como ilustra o comentário a seguir: "Dá para conciliar as atividades, esse trabalho não impede que eu trabalhe durante a semana" (cinegrafista, 7 anos de atuação no mercado informal).

Além disso, o primeiro grupo homogêneo de respostas permite dizer que as pessoas quando ingressam no mercado informal por influências de experiências pessoais, como o meio familiar e também por buscarem aplicar conhecimentos aprendidos em cursos, destacam os motivos de satisfação relacionados ao prazer, aos seus esforços e a dedicação na realização da atividade. Tal observação se exemplifica com o depoimento de que: "Minha primeira experiência foi com minha sogra que teve derrame, e hoje gosto do que faço, não adianta fazer uma coisa que não dá prazer, mas quero ainda fazer cursos de enfermagem" (cuidadora, 1 ano e 7 meses atuando no mercado informal).

No segundo grupo de respostas, localizado no lado direito da Figura 1, os motivos de ingresso escolha, melhoria da renda e desemprego mantêm correspondência com os motivos de satisfação, retorno e clientela. Assim, os trabalhadores que ingressaram no mercado informal por motivos de escolha pessoal, pela busca de melhor remuneração ou falta de oportunidades e de qualificação sinalizaram que há retorno quando este proporciona independência financeira e realização profissional pelo fato de estar ocupado. Tal associação assinalada pelo gráfico se expressa em falas, como: “Ao largar o emprego preferi voltar a trabalhar como informal, porque é mais vantagem financeira, ganho quase o dobro do que estaria recebendo se fosse com carteira assinada" (pintor, 35 anos de atuação no mercado informal); "Estava quase dois anos sem trabalhar, estou gostando porque acordo e sei o que vou fazer, antes não" (motorista, 4 meses de atuação no mercado informal). A satisfação também aparece quando se percebe que a clientela é fiel e os serviços prestados são avaliados como bons: "Não consegui retornar ao mercado (formal) e o bom é o atendimento, a qualidade do serviço que é positivo” (dona de lavanderia, 5 anos de atuação no mercado informal); "Queria uma remuneração melhor e hoje, sou bastante indicado, presto os serviços com qualidade e deixo o cliente satisfeito" (motorista, 6 anos de atuação no mercado informal).

Na Figura 2, que dispõe a correspondência entre motivos de ingresso e motivos de insatisfação, pode-se perceber, no grupo de respostas do lado esquerdo, que as pessoas que ingressaram pelos motivos de melhoria de renda, aplicação prática de curso, experiência anterior, complementação e desemprego apontaram como motivos de insatisfação a sustentação, investimento de capital e a clientela. O lado direito, por sua vez, traz à tona que as pessoas que ingressaram por escolha pessoal indicaram como motivo de insatisfação o retorno, como ilustra o seguinte comentário: "Entrei no mercado informal por opção, sempre gostei de música, sempre fiz isso (...) não estou satisfeito com meu trabalho porque viver de música no Brasil é complicado, estou ainda aquém do que pretendo" (professor de teclado, piano e violão, 10 anos de atuação no mercado informal). 


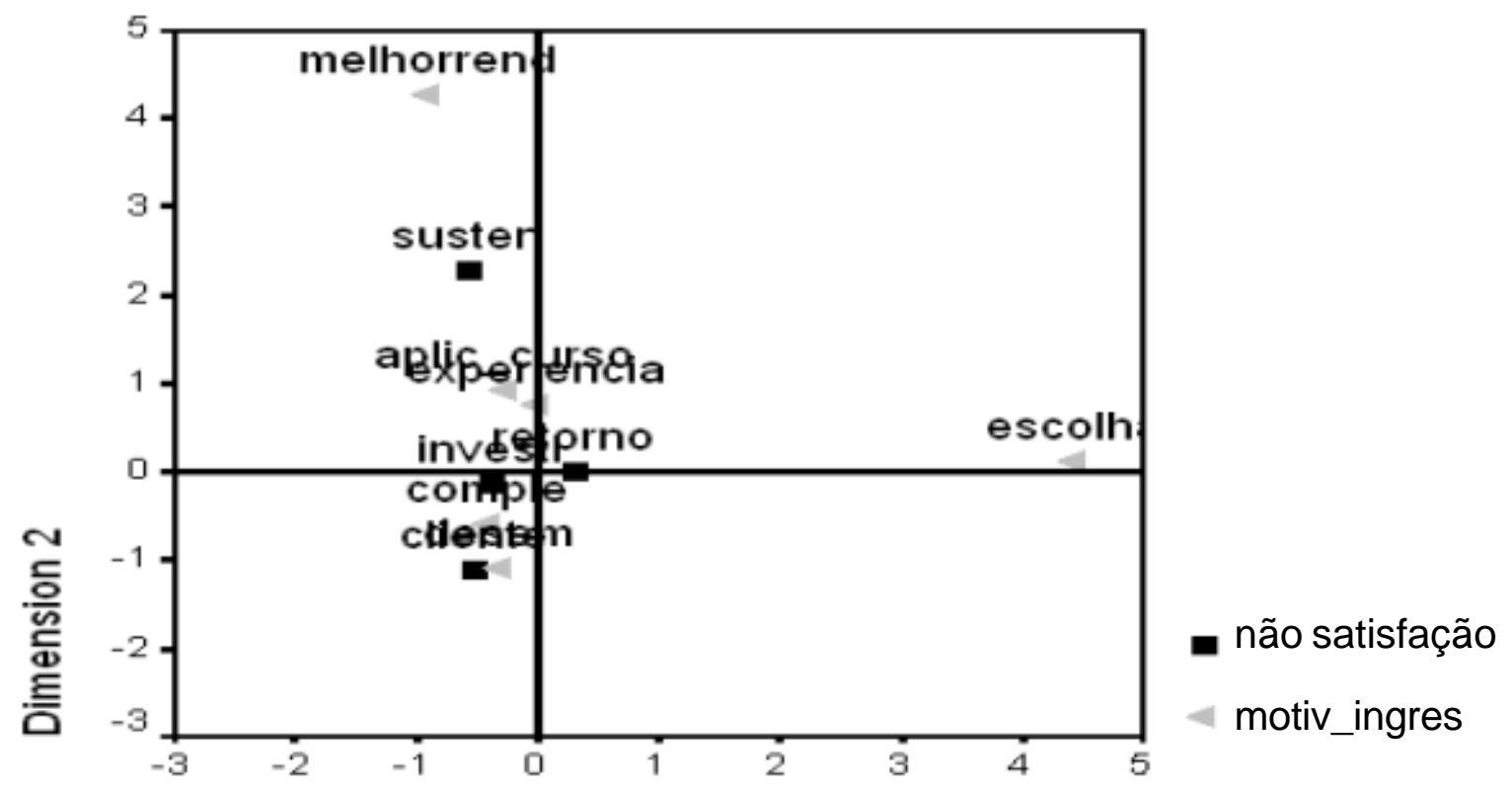

\section{Dimension 1}

Figura 2. Correspondência entre motivos de ingresso e motivos de insatisfação (valor próprio - dimensão 1: 0,942; dimensão 2: 0,822).

Na Figura 3 encontrou-se, no primeiro grupo de respostas (lado esquerdo), uma aproximação entre os motivos de ingresso complementação, escolha e melhoria na renda e as dificuldades com a concorrência, clientela e apoio do governo. As pessoas assinalaram existir pressão para a legalização, competição, dificuldade de efetuar cobranças e desconfiança do cliente, ao mesmo tempo em que destacaram a falta de apoio do governo, os impostos e a ausência de crédito. De certo modo, infere-se que há uma pressão da clientela para a garantia do serviço prestado, que seria obtida, por exemplo, pela emissão de notas fiscais. Somado a isso, a não disponibilidade de financiamentos da parte governo e a competitividade existente entre os setores formal e informal agravam o quadro de dificuldades enfrentado pelos trabalhadores, como relatado por dois deles. “A maior dificuldade é a falta de incentivo dos órgãos públicos; não obtenho financiamento, principalmente com a ferramenta que é o carro” (motorista, 6 anos de atuação); “A dificuldade é a concorrência das lojas que atualmente financiam carros usados em pequenas parcelas...” (vendedor de carro, 4 anos de atuação).

No segundo grupo de respostas (lado direito) da Figura 3 , os entrevistados que apontaram como motivos de ingresso a aplicação dos ensinamentos de curso, experiência e desemprego sinalizaram como dificuldades do trabalho informal, o retorno financeiro e a sustentação do negócio. Esses trabalhadores consideraram como barreiras para o trabalho informal, as dificuldades de divulgação (publicidade), a baixa capacidade de negociação e o custo de manutenção e matéria-prima, ou seja, a ausência de infra-estrutura, em decorrência da escassez de recursos para os investimentos necessári- os. O retorno insuficiente foi outra dificuldade apontada pelos entrevistados, atribuída ao rendimento incerto e a insegurança de rendimento. Um entrevistado se refere a tal situação: “A dificuldade é o medo e a ansiedade pela situação atual do país. Você não sabe quanto vai ganhar amanhã, daí não dá pra planejar. A área em que atuo é flutuante” (massagista, 3 anos e 6 meses de atuação).

O primeiro grupo homogêneo de respostas da Figura 4 indica que os motivos de satisfação clientela e sustentação estão relacionados com os motivos de insatisfação investimento e clientela. É importante salientar que a categoria clientela possui significados distintos em se tratando de motivos de satisfação e de insatisfação. Ao ser considerada como motivo de satisfação, a clientela tem como subcategorias mais expressivas a fidelidade do cliente e o bom serviço prestado, diferentemente da clientela como motivo da insatisfação, representada pelas subcategorias calote e dificuldade de cobrança, exploração, clientela sem dinheiro, sazonalidade da demanda e falta de reconhecimento.

O lado direito da mesma figura estabelece correlação entre os motivos de insatisfação e os de satisfação, permitindo afirmar que os entrevistados que apontaram o retorno e a sustentação como motivos de insatisfação indicaram também o investimento e o retorno como motivos de satisfação. O retorno em termos de satisfação diz respeito tanto à satisfação profissional quanto à satisfação financeira, ao passo que o retorno em se tratando de insatisfação diz respeito ao rendimento insuficiente e incerto bem com à ausência de direitos trabalhistas. O fato de o retorno aparecer tanto como motivo de satisfação quanto de insatisfação sinaliza a ambigüidade 


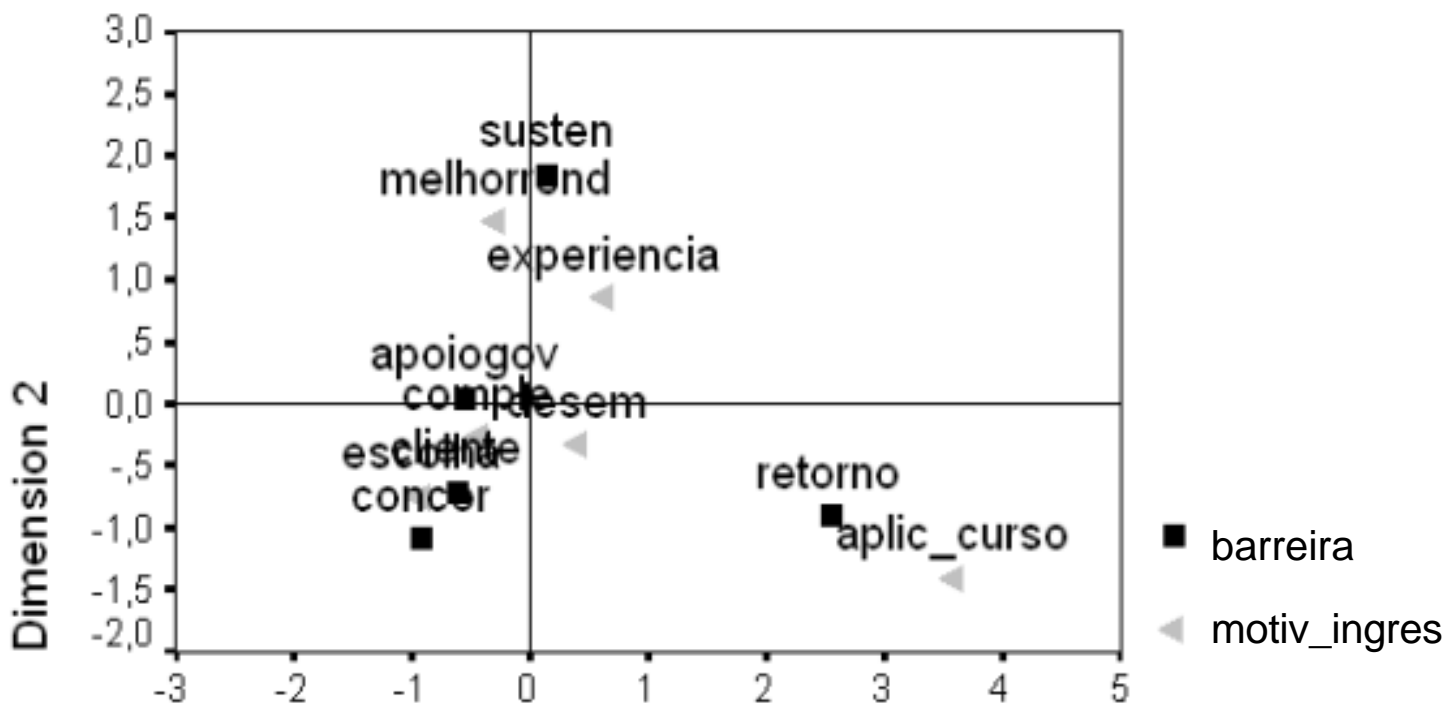

Dimension 1

Figura 3. Correspondência entre motivos de ingresso e barreiras (valor próprio - dimensão 1: 0,856; dimensão 2: 0,822).

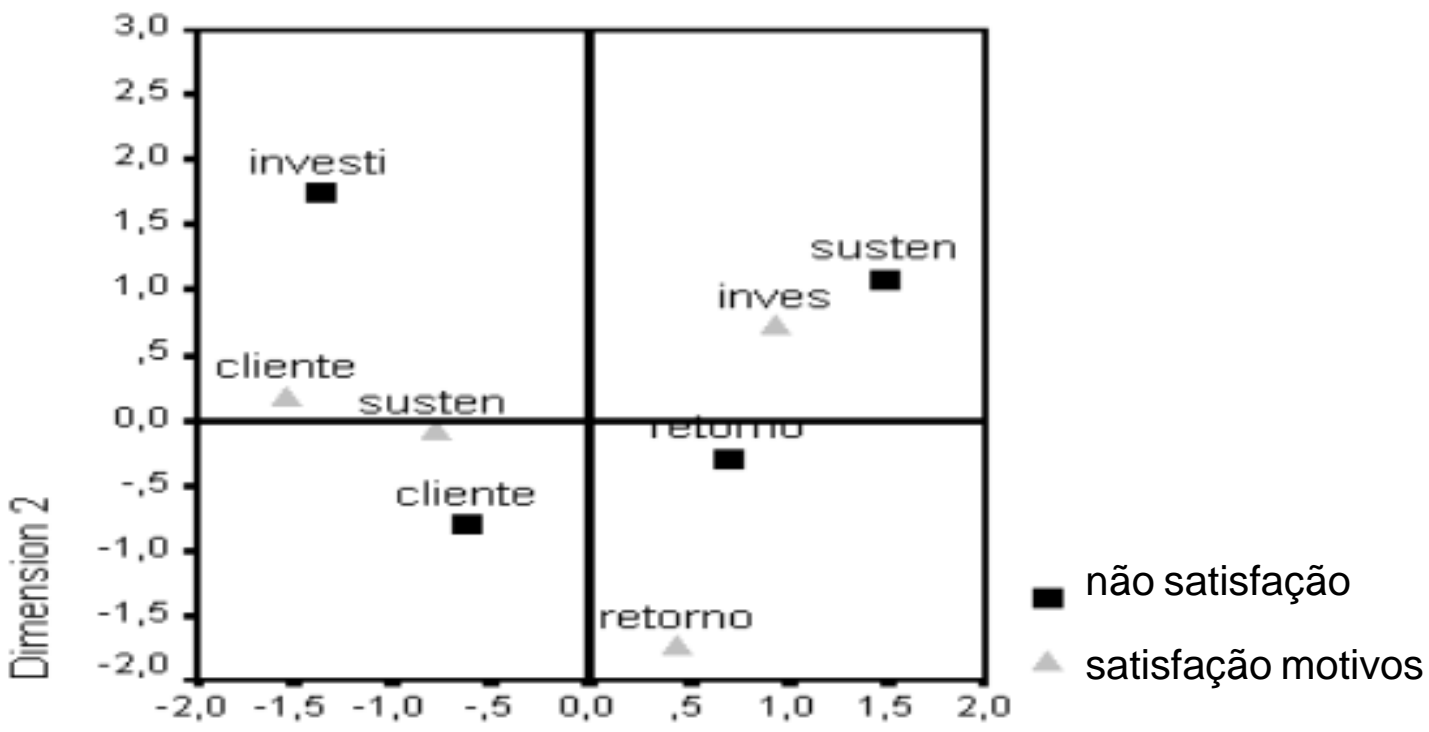

Dimension 1

Figura 4. Correspondência entre motivos de satisfação e motivos de insatisfação (valor próprio - dimensão 1: 0,844; dimensão 2: 0,713). 
desta categoria no mercado informal. Isso fica bem exemplificado nos comentários dos entrevistados: "Não estou satisfeita financeiramente, mas na minha satisfação sim, adoro" (costureira, 52 anos de atuação no mercado informal); "Me considero satisfeito porque me sustento com o meu trabalho, sou independente" (cinegrafista e fotógrafo, 7 anos de atuação no mercado informal). A fala da costureira também denota a situação na qual as pessoas sentem-se satisfeitas por exercerem atividades que gostam (investimento pessoal), mas a insatisfação aparece em relação à sustentação, pelas dificuldades com o custo da manutenção e da infra-estrutura.

\section{Considerações finais}

Como frisado no início deste texto, a pesquisa relatada tem pequeno alcance. $\mathrm{O}$ foco da análise realizada contemplou uma dimensão micro, enfocando menos os aspectos macroeconômicos, sociais e políticos que influenciam a expansão do mercado informal e mais as características e percepções de um segmento de trabalhadores que se encontra nesse mercado. Em virtude disto, as conclusões mencionadas nesta seção têm um escopo reduzido, embora não se possa negar que tragam à luz algumas pistas promissoras a serem exploradas em novas pesquisas.

Em outras palavras, é preciso reconhecer não ser por acaso haver muita diversidade conceitual entre mercado informal, setor informal e trabalho informal. Esta ausência de clareza conceitual revela a dificuldade em se delimitar com precisão os limites da informalidade, e isto se revela claro na análise empírica de um segmento deste mercado, objeto de análise dessa pesquisa. A categorização dos 638 anúncios em 19 áreas autoriza a concluir, ainda que parcialmente, a favor da dificuldade em demarcar o campo da informalidade, pois até o ponto em que foi possível constatar, ele abarca um conjunto de atividades bastante diversificadas.

Outro aspecto importante a ser acrescido é o de que este segmento de trabalhadores informais, a que se teve acesso por meio de registros de anúncios e de entrevistas telefônicas, caracteriza-se por ser um grupo de prestadores de serviços e de pequenos produtores e comerciantes com baixa capacidade de produção e pouco domínio de especialização. Não é por acaso que a segunda área temática de anúncios encontrada foi a multifuncional $(n=86)$, sendo constituída por aqueles que ofereciam vários tipos de serviços. A área temática de diversos apareceu em sétimo lugar $(n=34)$, incluindo profissionais que ofereciam serviços pouco passíveis de serem incluídos em uma área de atividade profissional convencional. Esta constatação reforça o ponto de vista de que o segmento informal está sendo ocupado por trabalhadores de baixa qualificação (a maior parte concluiu a ensino médio) que não conseguem se inserir no mercado formal de trabalho. Chamou a atenção o número expressivo de anúncios que mencionava mais a procura de empregos em determinadas áreas, ou seja, a condição de desocupado, do que a oferta de serviços.
O trabalhador informal se encontra principalmente na faixa dos 30 a 49 anos, concluiu o ensino médio e atua há 5 anos nesse mercado. É digno de nota destacar o curto tempo de permanência no setor na mesma atividade, constatado na etapa de entrevistas, pois muitos telefones estavam desatualizados ou as pessoas não mais ofereciam os mesmos serviços (quer porque tinham arranjado emprego, quer porque tinham desistido).

Somado a isto, a relação com a informalidade é ambivalente, o que se evidencia, por exemplo, pelo fato de uma mesma categoria ser mencionada tanto como fator de satisfação quanto de insatisfação, como foi o caso da clientela. Dito de outro modo, o trabalhador informal reconhece que sua sobrevivência no mercado depende significativamente da fidelidade da clientela e da boa qualidade da relação mantida entre as partes, mas admite que esta relação pode vir a ser tensa, em especial, em situações de cobrança de pagamento pelo trabalho já executado. Alguns poderiam contraargumentar dizendo que isto também ocorre no mercado formal, mas a diferença é a vulnerabilidade à clientela a que está sujeito o trabalhador informal quando comparado ao trabalhador formal. Enquanto a insatisfação do cliente gera impactos diretos no trabalhador informal, como o rompimento do vínculo, isto nem sempre ocorre com o trabalhador formal. Um vendedor de uma loja pode ter problemas com alguns clientes e o impacto ser maior para o vínculo que os últimos estabelecem com a loja ou empreendimento do que com a pessoa do vendedor. O cliente insatisfeito pode também não reclamar com o gerente e apenas deixar de freqüentar a loja. Se o cliente deixar de pagar uma prestação, é a loja que toma as providências para a cobrança de dívida, e não o vendedor que, a despeito do ocorrido, continua recebendo os seus vencimentos mensalmente.

O curto tempo de permanência na mesma atividade no mercado informal parece estar relacionado às dificuldades apontadas pelos entrevistados, em especial, a ausência de crédito e o apoio do governo, o que já foi apontado por Dalbosco (1999). Isto sinaliza para a necessidade de adoção de políticas públicas que visem a qualificar, oferecer linhas de crédito e normalizar procedimentos, o que poderá contribuir para formalizar atividades hoje do setor informal e para a sua concretização como alternativa para a geração de renda diante da crise da sociedade assalariada. Os trabalhadores informais, apesar de terem ingressado por acaso no mercado informal, sustentam a crença de que poderiam prosseguir neste ramo em que atuam, caso houvesse um programa de incentivo do governo, pois se sentem despreparados para enfrentar a concorrência e não dispõem de recursos para reinvestir e expandir o seu próprio negócio. Esta é uma das razões que os fazem desistir de atividades autônomas no mercado informal e persistir na busca de emprego formal, considerando-o mais seguro, principalmente por não terem de se preocupar com custos de manutenção do negócio, aspecto já apontado por Mafra et al., (2002). Trocando em miúdos, há uma ambivalência das instâncias governantes, pois apesar de enaltecerem fontes alternativas de geração de renda para o mercado formal, não oferecem condições neces- 
sárias para que os trabalhadores de baixa qualificação mantenham-se em atividades autônomas.

Para finalizar, cabe destacar uma vez mais o limitado poder de generalização dos resultados e conclusões aqui esboçadas para outros segmentos de trabalhadores informais. Entretanto, a urgência em se compreender de modo mais amplo e aprofundado um setor que cresce em tamanho e em complexidade, torna imperativo a realização de outras pesquisas envolvendo os diversos segmentos do setor informal, não só para confrontar, mas para complementar e aprofundar os dados que nos permitiram ter acesso a uma faceta da percepção subjetiva do trabalhador informal sobre a sua realidade sócio-ocupacional.

\section{Referências}

Bardin, L. (1970). Análise de conteúdo. Lisboa: Edições 70.

Bauer, M. W. (2002). Análise de conteúdo clássica: uma revisão. In M .W. Bauer \& Gaskell, G. (Orgs.), Pesquisa qualitativa com texto, imagem e som. Um manual prático (pp.189-217). Petrópolis: Vozes.

Borges, L. O., \& Yamamoto, O. H. (2004). O mundo do trabalho. In J. C. Zanelli, J. E. Borges-Andrade, \& A.V. B. Bastos (Orgs.), Psicologia, organizações e trabalho no Brasil (pp. 24-62). Porto Alegre: Artmed.

Central Única dos Trabalhadores - CUT (s.d.). O trabalho informal no Brasil. Recuperado em 20 de agosto de 2004, de www.cut.org.br/a50110.htm

Dalbosco, E. (1999). O trabalho informal no Brasil: análise, conceito, pesquisas e impactos sociais. Dissertação de mestrado não-publicada, Universidade de Brasília, Brasília.

Fagundes, M. E. M. (1992). Informalidade na Região Metropolitana de Salvador: um estudo exploratório. Dissertação de mestrado não-publicada, Universidade Federal da Bahia, Salvador.
Mafra, F. L. N., Tavares, T. S., Eiras, N. R. S., \& Mangini, D. (2002). Trabalho informal e qualidade de vida: interações possíveis no contexto local. Caderno de Pesquisas em Administração, 9(1), 103-115.

Morgan, G. A., \& Griego, O. V. (1998). Easy use and interpretation of SPSS for Windows. Answering research questions with statistics. Londres: Lawrence Erlbaum.

Morrone, C. F., \& Mendes, A. M. (2003) A resignificação do sofrimento psíquico no trabalho informal. Psicologia: Organizações e Trabalho, 3(2), 91-118.

Noronha, E. D. (2003). “Informal”, ilegal, injusto: percepções de mercado informal no Brasil. Revista Brasileira de Ciências Sociais, 18(53), 111-179.

Nunes, C. G. F. (2002). Cooperativas, uma possível transformação identitária para os trabalhadores do setor informal. Sociedade e Estado, 16(1-2), 134-158.

O trabalho informal avança rapidamente. (s.d.). Recuperado em 20 de agosto de 2004, de www2.uol.com.br/aprendiz/guiadeemprego/primeiro/noticias/geo010304.htm\#1

Oliveira, R. (2004). "Tudo é arriscado": a representação do trabalho entre trabalhadores informais da construção civil. Dissertação de mestrado nãopublicada, Universidade Federal da Bahia, Salvador.

Pastore, J. (2003). Onde estão os trabalhadores informais? Estado de São Paulo, de 03 de junho de 2003, p. B2. Recuperado em 20 de agosto de 2004, de http://www.josepastore.com.br/artigos/emprego/136.htm

Pestana, M. H., \& Gageiro, J. N. (1998). Análise de dados para ciências sociais. A complementaridade do SPSS. Lisboa: Silabo.

SEBRAE. (s.d.). Setor Informal Urbano - Pesquisa ECINF 1997. Recuperado em 20 de agosto de 2003, de http://www.sebrae.com.br/br/aprendasebrae/ economiainformalecinf1997.asp

Secretaria da Indústria e Comércio do Estado da Bahia (1983). O gigante invisível: estudo sobre o mercado informal do trabalho na região metropolitana de Salvador. Salvador: Autor.

Spínola, T. A. (2000). Informalidade em Salvador, uma questão de sobrevivência: o caso das costureiras da Boca do Rio. Dissertação de mestrado nãopublicada, Universidade Federal da Bahia, Salvador.

Sônia Maria Guedes Gondim, doutora em Psicologia pela Universidade Federal do Rio de Janeiro, é professora no Mestrado em Psicologia da Universidade Federal da Bahia. Endereço para correspondência: Rua Rodrigo Argolo, 293, apto 502; Jardim das Hortênsias, Rio Vermelho; Salvador, Bahia; CEP: 41.940.220. Tel.: (71)3240-7792 e 9165-3237. E-mail:sggondim@terra.com.br Girleide Novaes Feitosa, graduada em Psicologia pela Universidade Federal da Bahia, foi bolsista PIBIC, de agosto de 2003 a maio de 2004.

Ivna Christine de Novaes Santos é estudante de Psicologia na Universidade Federal da Bahia. Márcio de Oliveira Sá, graduado em Psicologia pela Universidade Federal da Bahia, foi bolsista PIBIC a partir de junho de 2004.

Mirele Cardoso do Bonfim é mestranda em Psicologia pela Universidade Federal da Bahia. 